\title{
DIRECT AND MATERNAL GENETIC PARAMETERS AND GENETIC TRENDS FOR SOME BODY WEIGHTS AND GROWTH TRAITS IN BARKI SHEEP
}

\author{
El-Wakil, Salwa* I. and S. M. A. Gad \\ Animal and Poultry Breeding Dept., Desert Research Centre, ElMatareya, Cairo, Egypt. \\ *Corresponding Email: salwa_elwakil@yahoo.com
}

\section{SUMMARY}

Body weight records of 3189 Barki lambs progenies of 186 sires and 1748 ewes were obtained from Barki sheep flock maintained at Ras Elhekma (from 1963 to 1972) and Maryout (from 1973 to 2004) research stations which belong to the Desert Research Centre in order to assess direct and maternal genetic parameters and genetic trends to evaluate the breeding strategies implemented for improving growth performance in Barki sheep. The present study dealt with body weights at birth, BW; weaning, $W W$ and yearling, $Y W$ as well as average daily gain from birth to weaning, DGBW and from weaning to yearling, DGWY. Data were analyzed by fitting a direct- maternal animal model using the MTDFREML program to estimate direct and maternal expected breeding values and correlations. Breeding values were plotted against year of birth to obtain genetic trends for the studied traits.

Results indicated the importance of maternal effects on the studied body weights and growth traits in Barki sheep. Maternal correlation coefficients (either genetic or environmental) were positive and higher than the corresponding phenotypic and direct ones. Genetic trend analysis for the studied traits indicated, on one hand, that there is virtually no difference between direct and maternal breeding values and hence genetic trends across the examined years which reveal that maternal genetic effects are of importance and probably have the same impact as the direct genetic effects. On the other hand, two distinct trends were clearly illustrated in which the positive genetic trends in body weight exhibited till 1975 - 1976 and then dropped and remained constant, thereafter. This time probably coordinated when the sheep flock had just moved from Ras Elhekma to Maryout research station. At Ras Elhekma research station, genetic progress achieved in the studied traits appeared to be generally significant and positive but of little magnitude throughout the examined years with slightly higher maternal genetic improvement compared with the respective direct genetic one. However, the annual direct and maternal genetic trends were generally negative, not significant and almost zeros at Maryout research station. Such no or minor genetic response exhibited for the studied traits during the evaluated years might be a result of lacking effective directional selection, management system applied and incompatible environmental conditions. Likewise, it could probably be attributed to neglecting the maternal influences either genetic or environmental throughout the implementation of breeding program which used to depend entirely on direct genetic effects. Implications of including both direct and maternal effects into the breeding program to improve growth performance in Barki sheep have been discussed.

\section{Keywords: Body weights, genetic parameters, maternal effects, genetic trend, Barki sheep}

\section{INTRODUCTION}

Most livestock are mammals with long history of maternal dependence, hence, maternal effects could be described as any contribution of a mother that affects the phenotypic expression of her offspring; it has genetic and environmental components (Szwaczkowski et al., 2006; Ghafouri-Kesbi and Eskandarinasab, 2008). Some published reports demonstrated that not just the animal's own genetic effect, but the maternal effects such as additive maternal genetic and/ or permanent environmental effects are important in the expression of animal performance and could significantly affect body weights and growth traits in sheep (Senemari et al., 2011; Rashidi, 2012 and Shokrollahi and Baneh, 2012). Accounting for maternal effects would increase accuracy of selection since it explains much of the variation in body weights and growth parameters (Burfening and Kress, 1993 and Maria et al., 1993). On the other hand, Barki sheep is a native breed raised in the north western desert of Egypt. They are fat-tailed sheep and well adapted to harsh climatic conditions and scarce vegetation. Since early sixties, Barki sheep flock of the Desert Research Centre has been subjected to a selection program based mainly on body weight to attain optimum growth and well adapted animals to increase the efficiency of the prevailing production system. That breeding program has been evaluated recently from the perspectives of genetic, phenotypic and environmental trends for some body weights (ElWakil and Elsayed, 2013). The idea of the present study came to the interest since the importance of maternal effects on body weights of Barki sheep has been emphasized recently (El-Wakil and Gad, 2014) and the implications of maternal influences on the genetic improvement program has not been fully investigated in Barki sheep. It would be of interest to study direct and maternal genetic correlations among the studied traits and asses such implemented breeding program by investigating direct and 
maternal genetic trends as a very useful tool to evaluate the selection strategies in the population over specific time. Thus, the current investigation aimed to improve the quality of genetic parameters by fitting the aspects of both direct and maternal effects into the statistical model to increase the accuracy of selection and consequently help breeders to fine tuning the breeding strategies to ensure adequate genetic evaluation and selection response for growth performance in Barki sheep.

\section{MATERIALS AND METHODS}

\section{Data}

A set of body weight records and pedigree information of 3189 Barki lambs progenies of 186 sires and 1748 ewes, used in the present study were originated from the sheep flock of the Desert Research Centre maintained at two research stations; Ras Elhekma (from 1963 to 1972) and Maryout (from 1973 to 2004). Management of the flock was almost the same where ewes were often first mated at approximately 16 months of age. The breeding season usually carried out once a year in June - July to start lambing at October - November. At birth, lambs were weighed to assign birth weight, then body weights were recorded at biweekly interval till weaning followed by monthly interval till the animal removed from the flock. Shearing took place once a year during April- May. Feeding of the flock depends mainly on grazing at Ras Elhekma while rely on cut and carry at Maryout research station. Detailed flock management was described by El-Wakil et al. (2009).

The present study dealt with body weights at birth, $B W$; weaning, 120 days, $W W$ and yearling, 360 days, $Y W$. Average daily gain was also calculated from birth to weaning, $D G B W$ and from weaning to yearling, $D G W Y$. $B W$ was kept as recorded while $W W$ and $Y W$ were linearly adjusted to body weights at 120 and 360 days, respectively. The adjustments for individual body weights to different ages were made by interpolation between the data of two successive ages assuming linear growth function during the short intervals. $D G B W$ and $D G W Y$ were calculated as the appropriate difference between birth to weaning body weights and between weaning to yearling body weights, respectively divided by the exact number of appropriate days from birth till weaning and from weaning up to 360 days, respectively. Editing of the original data was done to remove the few numbers of twinning from the data set together with those animals that had missing identifications. Table (1) presented the characteristics of the data structure introduced in statistical analysis.

\section{Statistical analysis:}

Using the general linear model (GLM) procedure of SAS (2004), preliminary analyses were conducted and indicated that lamb gender, dam age, location and year of birth within location are significant fixed effects for the studied traits in this set of data.
Consequently, they were introduced for further analysis by fitting an animal model using the MTDFREML program (Boldman et al., 1995). While there is a series of models including various combinations of maternal and direct effects could be fitted, the following model was chosen since it has all portions from which all (co) variance components could be obtained to calculate the required genetic parameters. The model included the same fixed effects mentioned earlier and considering the animal, sire and dam as random effects as follows:

\section{$\mathbf{Y}=\mathbf{X b}+\mathbf{Z}_{\mathrm{a}} \mathbf{a}+\mathbf{Z}_{\mathrm{m}} \mathbf{m}+\mathbf{Z}_{\mathrm{c}} \mathbf{c}+\mathbf{e}$, where \\ $\operatorname{Cov}(\mathbf{a}, \mathbf{m})=A \sigma_{\mathrm{am}}$}

where $\mathrm{Y}$ is a vector of observations on the studied trait; b, a, m, c and e are vectors of fixed effects, direct additive genetic effects, maternal additive genetic effects, maternal permanent environmental effects and the residual effects, respectively. $X, Z_{a}$, $\mathrm{Z}_{\mathrm{m}}$ and $\mathrm{Z}_{\mathrm{c}}$ are incidence matrices relating observations to the fixed effects, direct additive genetic effects, maternal additive genetic effects and maternal permanent environmental effects, respectively. It was assumed that direct additive genetic, maternal additive genetic, maternal permanent environmental and residual effects to be normally distributed with mean of zero and variance of $A \sigma_{a}^{2}, A \sigma_{m}^{2}, I_{d} \sigma^{2} c$ and $I_{n} \sigma_{e}^{2}$, respectively; where $\sigma_{a}^{2}$, $\sigma_{m}^{2}, \sigma_{c}^{2}$ and $\sigma_{e}^{2}$ are direct additive genetic variance, maternal additive genetic variance, maternal permanent environmental variance and the residual variance, respectively. " $\mathrm{A}$ " is the additive numerator relationship matrix, while $I_{d}, I_{1}$ and $I_{n}$ are identity matrices with dimensions equal to the number of the dams and number of records, respectively. Moreover, $\sigma_{\mathrm{am}}$ refers to the covariance between direct additive genetic and maternal additive genetic effects.

(Co) variance components were used to estimate correlation coefficients among the studied traits. Estimates of simple correlations between studied traits were done using a series of bivariate analyses. The appropriate covariance, phenotypic or genetic, between each pair of studied traits, $\mathrm{x}$ and $\mathrm{y}$, was divided by the square root of the product of the phenotypic variance of each trait $\left(\mathbf{r}_{\mathbf{x y}}=\boldsymbol{\sigma x y} / \sqrt{ }\right.$ $\left(\sigma_{x}^{2} * \sigma_{y}^{2}\right)$. The maternal genetic, maternal permanent environmental and direct environmental correlations were calculated in the same manner.

Additive (ABVs) and maternal breeding values (MBVs) of individual animals were estimated using the direct-maternal animal model previously mentioned through MTDFREML software (Boldman et al., 1995). Consequently, the mean values of ABVs and MBVs were calculated according to birth years. The average estimated breeding values were regressed and plotted on year of birth to predict annual direct and maternal genetic trends for the studied traits (Ahmad, 2007). These procedures were carried out using SAS computer package (SAS, 2004). 


\section{RESULTS AND DISCUSSION}

Table (1) showed averages of the studied body weights and growth traits. It appeared that body weight increased as age advanced while the efficiency of growth measured in terms of daily gain in body weight occurred during the pre-weaning stage $(D G B W)$ was twice as much as post-weaning daily gain $(D G W Y)$. Moreover, $B W$ seemed to have the least variations in terms of standard errors and coefficient of variation. As age advanced from birth to weaning to yearling, variations tend to generally increase, probably a reflection of different management, feeding strategies and climatic conditions, hence the relatively high standard errors and coefficients of variation were obtained. This might indicate the smaller effect of environment on $B W$ compared with $W W$ and $Y W$. Similar findings were reported in the literature (Snyman et al., 1995; Miraei- Ashtiani et al., 2007 and Senemari et al., 2011).

\section{Correlation coefficients}

Maternal correlation coefficients (either genetic or environmental) among the studied body weights $(B W, W W$ and $Y W$ ) appeared to be positive and higher than the corresponding phenotypic and direct ones (either genetic or environmental) as seen from Table (2). These results probably emphasize the importance of maternal effects to control the studied body weights and growth traits in Barki sheep as reported earlier by El-Wakil and Gad (2014). It seems that body weight from birth to the yearling stage is largely influenced by similar genes of the dam in terms of maternal genetic effects. The maternal additive genetic and environmental effects, which favor the growth of fetus, could also have some beneficial effect on post-natal growth traits. Similar explanations were reported elsewhere (Maria et al., 1993; Gowane et al., 2010; Rashidi, 2012 and Ghafouri-Kesbi and Baneh, 2012).

Generally higher genetic correlations (direct or maternal) obtained among $B W, W W$ and $Y W$ compared with the respective phenotypic ones could probably be due to less environmental factors (or correlations) affecting these traits. The maternal permanent environmental correlations were generally positive and being consistently higher than the corresponding phenotypic, genetic and direct environmental correlations which might indicate the similarity of environmental conditions in which the studied traits are measured. This also demonstrates the importance of maternal environment to control these traits and suggest that good management conditions and favorable maternal behavior would have a positive influence on body weight of lambs at birth up to the yearling stage. The maternal environmental effects on body weights could possibly be determined by uterine capacity, feeding level during late gestation and maternal behavior of the ewe (Gowane et al., 2010; Thiruvenkadan et al., 2011; Rashidi, 2012 and Shokrollahi and Baneh, 2012).
Phenotypic, direct genetic, maternal genetic, direct environmental and maternal permanent environmental correlations among $B W, W W$ and $Y W$ were all positive and ranged between 0.20 and 1.00 which imply no antagonism relationship among these traits (Table 2). Thus, selection for increased body weight at certain stage would result in genetic improvement in the subsequent development of body weight, which will be reflected on the average daily weight gain during the pre- and post-weaning stages of development. More specifically, weaning weight had a positive and strong correlation with yearling weight in terms of phenotypic, direct and maternal genetic as well as direct and maternal permanent environmental correlations. These correlations were stronger than corresponding ones for $B W$ with either $W W$ or $Y W$. Similar findings were obtained earlier in the same flock (El-Wakil et al., 2009) and have been found recently (Shokrollahi and Baneh, 2012). Such higher genetic correlations (direct and maternal) between $W W$ and $Y W$ probably implied that they have a similar pattern of gene expression affecting growth at weaning and yearling stages. Thus, selection based on $W W$ may help to improve $Y W$ in Barki sheep. However, negative direct-maternal additive genetic correlations attained for $W W$, although with little magnitude (-0.07, Table 3), indicate that further selection of animals by considering only high direct additive genetic values could decline the maternal ability for body weight at yearling stage. Thus, the breeders have to consider these antagonistic relationships within and between traits during selection process in order to improve the genetic progress in this flock. Similar findings were reported by Tosh and Kemp (1994) and Supakorn et al. (2013).

Phenotypic and additive genetic correlations of $B W$ with $W W$ (0.33 and 0.37 , respectively) were higher than that of $B W$ with $Y W(0.30$ and 0.25 , respectively). This result is expected since the chronologically adjacent weight traits have the largest positive relationship rather than non-adjacent ones which revealed that an autocorrelation would exist among the genetic and environmental effects associated with the successive measurements (Mousa et al., 1999; Senemari et al., 2011). Such explanation perhaps does not exist with the maternal genetic and maternal permanent environmental correlations of $B W$ with $W W(0.73$ and 0.78 , respectively) where the opposite pattern was detected compared with the corresponding correlations of $B W$ with $Y W(0.81$ and 1.00 , respectively). This might indicate that body weights at later ages are largely controlled by the same genes or maternal effects. Similar findings were reported by Senemari et al. (2011) and also confirms the results obtained in Barki sheep (El-Wakil and Gad, 2014) in which total maternal components tended to be maintained and being relatively constant at a level of about $20 \%$ from birth to the yearling stage. 
Table 1. Characteristics of the data structure for the studied traits

\begin{tabular}{lcccc}
\hline & No of records & Mean $(\mathbf{k g})$ & S.E. $(\mathbf{k g})$ & C.V. $(\%)$ \\
\hline $\begin{array}{l}\text { No. of animals } \\
\text { No. of sires }\end{array}$ & 3189 & & & \\
No of dams & 186 & & & \\
BW & 1748 & & & 17.92 \\
WW & 3189 & 3.54 & 0.01 & 24.01 \\
YW & 2780 & 17.51 & 0.08 & 22.90 \\
DGBW & 1717 & 31.56 & 0.17 & 29.02 \\
DGWY & 2780 & 0.116 & 0.64 & 41.31 \\
\hline
\end{tabular}

$\boldsymbol{B} \boldsymbol{W}=$ birth weight, $\boldsymbol{W W}=$ weaning weight, $\boldsymbol{Y W}=$ yearling weight, $\boldsymbol{D G B W}=$ daily gain from birth to weaning, and $\boldsymbol{D G W}=$ daily gain from weaning to yearling.

The correlations of $D G B W$ with $D G W Y$ were the highest in terms of maternal permanent environmental (0.99) followed by the phenotypic (0.60) and direct genetic ones (0.32). The correlations of $D G B W$ with the studied body weights were all positive and ranged from 0.05 to 1.00 while the only exception was the negative maternal permanent environmental correlation of -1.0 between $W W$ and $D G B W$. Phenotypic, direct genetic and maternal genetic correlations of $D G B W$ with studied body weights were higher than the corresponding ones for $D G W Y$. On the other hand, direct and maternal genetic correlations of $D G W Y$ with the studied traits were generally positive, with few exceptions for negative direct genetic correlations obtained for $D G W Y$ with both $W W(-0.12)$ and $Y W(-0.21)$ together with negative maternal genetic correlations for $D G W Y$ with $W Y(-0.61)$ and $D G B W(-0.08)$ which imply genetic antagonisms among these traits.

\section{Breeding values}

Table (3) presents direct and maternal parameters estimated from the direct-maternal animal model. The estimated direct and maternal breeding values for the studied traits were very close and fluctuated across the examined years (Table 4). Direct breeding values were estimated for $B W$ (ranged from $-0.001 \mathrm{~kg}$ to $0.111 \mathrm{~kg}$ ), $W W$ (from $-0.024 \mathrm{~kg}$ to $1.285 \mathrm{~kg}$ ), $Y W$ (from $0.005 \mathrm{~kg}$ to $1.417 \mathrm{~kg}$ ), $D G B W$ (from $-0.060 \mathrm{gm}$ to $9.772 \mathrm{gm}$ ) and $D G W Y$ (from $0.004 \mathrm{gm}$ to 1.977 $\mathrm{gm})$. The corresponding maternal breeding values were found to be ranged from $0.001 \mathrm{~kg}$ to $0.204 \mathrm{~kg}$, $0.009 \mathrm{~kg}$ to $1.027 \mathrm{~kg}, 0.010 \mathrm{~kg}$ to $1.713 \mathrm{~kg}, 0.002 \mathrm{gm}$ to $7.510 \mathrm{gm}$ and $0.001 \mathrm{gm}$ to $1.09 \mathrm{gm}$, for $B W, W W$, $Y W, D G B W$ and $D G W Y$, respectively. Moreover, simple correlation coefficients between direct and maternal breeding values across the examined years were found to be high and positive for $B W(0.85)$, $W W(0.89), Y W(0.98)$ and $D G B W(0.86)$ while being negative for $D G W Y(-0.79)$. Genetic trend analysis (Table 4 and Figs. 1-5) for the studied traits indicated, on one hand, that there is virtually no difference between direct and maternal genetic trends which reveal that maternal genetic effects are of importance and probably have the same impact as the direct genetic effects. On the other hand, two distinct trends were clearly illustrated from figures (1 to 5). In 1975-1976, the positive genetic trends in body weight dropped and thereafter it remained constant. This time probably coordinated when the sheep flock had just moved from Ras Elhekma to Maryout research station. It is also matched with the positive trend occurred in Ras ElHekma and the negative one happened in Maryout as appeared in Table (5). In Ras Elhekma research station, genetic progress achieved in the studied body weights and growth traits appeared to be generally significant and positive but of little magnitude throughout the examined years with slightly higher maternal genetic improvement compared with the respective direct genetic one. Although the annual maternal genetic trend exhibited slightly higher and positive estimates than the annual additive genetic trend for $B W, W W, Y W$ and $D G B W$, it showed lower and negative estimate for $D G W Y$. The magnitude of genetic trends seemed to be increased as age advanced with the largest improvement detected for $Y W$ (Table 5). On the other hand, the annual direct and maternal genetic trends were generally negative, not significant and almost zeros for all studied traits at Maryout research station. Such no or minor genetic response exhibited for the studied traits during the evaluated years could be a result of lacking effective directional selection (Ulutas et al., 2010), management system applied and incompatible environmental conditions. Similar findings were reported elsewhere (Thiruvenkadan et al., 2011 and Shokrollahi and Baneh, 2012). It is worthwhile mentioning that most of the selection emphasis implemented since the establishment of this flock has been based entirely on direct genetic effects while neglecting the maternal influences either genetic or environmental. This could be another explanation for such minor improvements obtained for the studied traits over the examined period which probably resulted in inferior maternal behavior especially effects of the uterine environment and extra-chromosomal inheritance or else. 


\section{CONCLUSION}

It appeared from the previous (El-Wakil and Gad, 2014) and current investigation that maternal genetic parameters in terms of heritabilities and both genetic and permanent environmental correlations were consistently higher than the corresponding direct ones for the studied body weights and growth traits in Barki sheep. Furthermore, maternal breeding values seemed to be as important and have perhaps the same impact as the direct breeding values in controlling the studied traits and hence should be considered in the genetic evaluation of Barki sheep. The breeding program has to be modified to include the maternal effects which could mask true genetic potential of Barki lambs. To improve the genetic merit of breeding animals, selection should be based on breeding values estimated through a model assuming direct and maternal effects and the covariance between them within and between the target traits. For genetic improvement in maternal performance, selection of rams and ewes must depend entirely on maternal breeding values in order to improve ewe traits in particular and hence improve mothering abilities faster. Selection based on maternal breeding values would affect genetic improvement through focusing on ewe performance and ensure precise estimate of the direct breeding values for a given trait by taking account of the maternal effects. Moreover, care must be taken to minimize the impact of negative correlations between direct and maternal genetic effects for target traits through an appropriate balance between these two types of effects. It is also of importance to realize that genetic progress could be achieved in growth performance of Barki sheep if reasonable levels of flock management as well as selection pressure are maintained.

Table 2. Correlations among body weights at birth $(B W)$, weaning $(W W)$ and yearling $(Y W)$ as well as average daily gain from birth to weaning $(D G B W)$ and from weaning to yearling $(D G W Y)$

\begin{tabular}{|c|c|c|c|c|c|c|}
\hline Trait1 & Trait2 & $\mathbf{r}_{\mathrm{p} 1 \mathrm{p} 2}$ & $\mathbf{r}_{\mathrm{a} 1 \mathrm{a} 2}$ & $\mathbf{r}_{\mathrm{m} 1 \mathrm{~m} 2}$ & $\mathbf{r}_{\mathrm{c} 1 \mathrm{c} 2}$ & $\mathbf{r}_{\mathrm{e} 1 \mathrm{e} 2}$ \\
\hline \multirow[t]{4}{*}{ BW } & WW & $0.33^{* *}$ & $0.37 * *$ & $0.73 * *$ & $0.78 * *$ & $0.20 * *$ \\
\hline & YW & $0.30 * *$ & $0.25 * *$ & $0.81 * *$ & $1.00 * *$ & $0.21 * *$ \\
\hline & DGBW & $0.18 * *$ & $0.23 * *$ & $0.65^{* *}$ & $0.27 * *$ & 0.05 \\
\hline & DGWY & $0.13^{* *}$ & $0.09 *$ & $0.84 * *$ & $-1.00 * *$ & 0.06 \\
\hline \multirow[t]{3}{*}{ WW } & YW & $0.65^{* *}$ & $0.86 * *$ & $1.00 * *$ & $1.00 * *$ & $0.50 * *$ \\
\hline & DGBW & $0.95^{* *}$ & $0.81 * *$ & $0.87 * *$ & $-1.00 * *$ & $0.99 * *$ \\
\hline & DGWY & 0.02 & $-0.12 * *$ & $0.27 * *$ & $1.00 * *$ & -0.01 \\
\hline \multirow[t]{2}{*}{ YW } & DGBW & $0.64 * *$ & $0.75^{* *}$ & $1.00 * *$ & $1.00 * *$ & $0.48 * *$ \\
\hline & DGWY & $0.60 * *$ & $-0.21 * *$ & $-0.61 * *$ & $1.00 * *$ & $0.94 * *$ \\
\hline DGBW & DGWY & $0.60 * *$ & $0.32 * *$ & -0.08 & $0.99 * *$ & $-0.09 *$ \\
\hline
\end{tabular}

$\boldsymbol{r}_{\boldsymbol{p l p 2} 2}=$ phenotypic correlation, $\boldsymbol{r}_{\boldsymbol{a l a 2}}=$ direct genetic correlation, $\boldsymbol{r}_{\boldsymbol{m} \mathbf{I m} 2}=$ maternal genetic correlation, $\boldsymbol{r}_{\boldsymbol{c l c} 2}=$ maternal permanent environmental correlation and $\boldsymbol{r}_{\text {ele }}=$ direct environmental correlation $(* \mathrm{P}<0.05$ and $* * \mathrm{P}<0.01)$.

Table 3. Direct and maternal parameters for birth weight $(B W)$, weaning weight $(W W)$ and yearling weight $(Y W)$ as well as average daily gain from birth to weaning $(D G B W)$ and from weaning to yearling $(D G W Y)$ estimated from the direct-maternal animal model

\begin{tabular}{llllll}
\hline Trait & $\mathbf{h}_{\mathbf{d}}^{\mathbf{2}}$ & $\mathbf{h}_{\mathbf{m}}^{\mathbf{2}}$ & $\mathbf{c}^{\mathbf{2}}$ & $\mathbf{r}_{\mathbf{a m}}$ & $\boldsymbol{\sigma}_{\mathbf{p}}^{\mathbf{2}}$ \\
\hline BW & 0.10 & 0.18 & 0.00 & 0.22 & 0.36 \\
WW & 0.14 & 0.13 & 0.07 & -0.07 & 12.71 \\
YW & 0.07 & 0.12 & 0.04 & 0.35 & 32.30 \\
DGBW & 0.14 & 0.12 & 0.05 & -0.16 & 810.47 \\
DGWY & 0.10 & 0.07 & 0.00 & -0.72 & 318.82
\end{tabular}

$\boldsymbol{h}_{\boldsymbol{d}}^{2}=$ direct heritability, $\boldsymbol{h}_{\boldsymbol{m}}^{2}=$ maternal heritability, $\boldsymbol{c}^{2}=$ ratio of permanent environmental variance to total variance, $\boldsymbol{r}_{\boldsymbol{a m}}=$ correlation of additive genetic effects and maternal genetic effects, $\sigma_{p}^{2}=$ phenotypic variance. 
Table 4. Estimated least square means $(\mathrm{kg})$ of animal direct $(D B V)$ and maternal $(M B V)$ breeding values for birth $(B W)$, weaning $(W W)$ and yearling $(Y W)$ body weights as well as daily gain from birth to weaning $(D G B W)$ and from weaning to yearling $(D G W Y)$ calculated according to birth years within location

\begin{tabular}{|c|c|c|c|c|c|c|c|c|c|c|}
\hline \multirow{3}{*}{ Year } & \multicolumn{10}{|c|}{ Estimated least square means of animal breeding values } \\
\hline & \multicolumn{2}{|c|}{ BW } & \multicolumn{2}{|c|}{ WW } & \multicolumn{2}{|c|}{ YW } & \multicolumn{2}{|c|}{ DGBW } & \multicolumn{2}{|c|}{ DGWY } \\
\hline & DBV & MBV & DBV & MBV & DBV & MBV & DBV & MBV & DBV & MBV \\
\hline \multicolumn{11}{|c|}{ Ras Elhekma } \\
\hline 1963 & -0.023 & -0.028 & -0.131 & 0.042 & -0.095 & 0.146 & -0.867 & 0.452 & -1.462 & 1.090 \\
\hline 1964 & -0.031 & -0.018 & 0.122 & -0.009 & 0.128 & 0.123 & 1.518 & 0.119 & -0.322 & 0.343 \\
\hline 1965 & -0.006 & -0.027 & 0.048 & -0.015 & 0.144 & 0.010 & 0.539 & 0.186 & 0.137 & 0.001 \\
\hline 1966 & -0.006 & -0.036 & -0.076 & 0.129 & 0.341 & 0.282 & -0.650 & 1.44 & 0.941 & -0.315 \\
\hline 1967 & -0.016 & -0.002 & -0.024 & 0.165 & 0.088 & 0.081 & -0.060 & 1.534 & -0.079 & 0.061 \\
\hline 1968 & 0.029 & 0.020 & -0.201 & 0.183 & 0.329 & 0.422 & 1.343 & 1.461 & -0.026 & 0.308 \\
\hline 1969 & 0.018 & 0.030 & 0.208 & 0.189 & 0.180 & 0.268 & 1.514 & 1.436 & -0.251 & 0.290 \\
\hline 1970 & 0.035 & 0.023 & 0.349 & 0.382 & 0.483 & 0.646 & 2.465 & 3.053 & 0.078 & 0.194 \\
\hline 1971 & 0.096 & 0.204 & 0.589 & 1.027 & 0.899 & 1.429 & 3.580 & 7.175 & 0.275 & 0.543 \\
\hline 1972 & 0.044 & 0.040 & 0.709 & 0.573 & 0.950 & 1.149 & 5.342 & 4.336 & 1.283 & -0.169 \\
\hline \multicolumn{11}{|c|}{ Maryout } \\
\hline 1973 & 0.111 & 0.101 & 0.845 & 0.942 & 0.872 & 1.407 & 5.769 & 6.873 & 0.318 & 0.440 \\
\hline 1975 & 0.061 & 0.038 & 1.285 & 1.010 & 1.417 & 1.713 & 9.772 & 7.510 & 1.977 & -0.441 \\
\hline 1976 & 0.099 & 0.080 & 1.160 & 0.899 & 1.334 & 1.604 & 8.367 & 6.365 & 1.719 & -0.430 \\
\hline 1977 & 0.060 & 0.045 & 0.813 & 0.545 & 0.676 & 0.849 & 6.059 & 3.860 & 0.738 & -0.143 \\
\hline 1984 & -0.018 & -0.020 & -0.08 & 0.033 & -0.107 & -0.08 & -0.588 & 0.395 & -0.138 & -0.052 \\
\hline 1989 & 0.003 & 0.010 & 0.080 & 0.073 & 0.108 & 0.152 & 0.553 & 0.485 & 0.014 & 0.082 \\
\hline 1990 & -0.003 & 0.009 & 0.036 & -0.025 & 0.026 & 0.063 & 0.376 & -0.257 & 0.004 & -0.012 \\
\hline 1992 & -0.001 & 0.011 & 0.145 & 0.054 & 0.127 & 0.105 & 0.903 & 0.326 & 0.355 & -0.182 \\
\hline 1994 & 0.038 & 0.051 & 0.077 & 0.278 & 0.174 & 0.297 & 0.333 & 2.019 & -0.008 & 0.133 \\
\hline 1995 & 0.009 & 0.026 & 0.228 & 0.201 & 0.280 & 0.436 & 1.644 & 1.367 & 0.021 & 0.217 \\
\hline 1997 & -0.011 & 0.013 & -0.083 & 0.027 & 0.005 & 0.011 & -0.611 & 0.209 & -0.016 & 0.014 \\
\hline 1998 & 0.008 & 0.012 & 0.032 & 0.095 & 0.120 & 0.126 & 0.226 & 0.691 & 0.379 & -0.230 \\
\hline 1999 & -0.003 & 0.012 & 0.056 & 0.108 & 0.120 & 0.150 & 0.459 & 0.786 & 0.262 & -0.128 \\
\hline 2000 & 0.023 & 0.046 & 0.280 & 0.068 & 0.253 & 0.274 & 2.060 & 0.169 & 0.517 & -0.205 \\
\hline 2001 & 0.011 & 0.011 & -0.029 & 0.025 & 0.072 & 0.113 & -0.178 & 0.194 & 0.060 & 0.038 \\
\hline 2002 & 0.018 & 0.033 & 0.154 & 0.029 & 0.112 & 0.096 & 1.058 & 0.002 & 0.072 & 0.013 \\
\hline 2003 & 0.006 & 0.010 & 0.120 & 0.055 & 0.026 & 0.071 & 0.939 & 0.318 & -0.121 & 0.121 \\
\hline 2004 & -0.003 & 0.001 & 0.124 & 0.013 & 0.041 & 0.054 & 1.067 & 0.028 & -0.005 & 0.036 \\
\hline
\end{tabular}

Table 5. Direct and maternal genetic trends \pm SE for birth weight $(B W, \mathbf{k g})$, weaning weight $(W W, \mathbf{k g})$, yearling weight $(Y W, \mathrm{~kg})$, daily gain from birth to weaning $(D G B W, \mathrm{gm})$ and from weaning to yearling stages $(D G W Y, g m)$ in Ras Elhekma and Maryout research stations

\begin{tabular}{lllllll}
\hline Trend & & \multicolumn{1}{c}{ BW } & \multicolumn{1}{c}{ WW } & \multicolumn{1}{c}{ YW } & \multicolumn{1}{c}{ DGBW } & \multicolumn{1}{c}{ DGWY } \\
\hline Additive & Ras Elhekma & $10.99 \pm 0.0^{*}$ & $78.84 \pm 0.0^{*}$ & $98.52 \pm 0.0^{*}$ & $532.36 \pm 0.1^{*}$ & $151.92 \pm 0.1^{*}$ \\
Genetic & Maryout & $-0.01 \pm 0.0$ & $-0.12 \pm 0.0$ & $-0.16 \pm 0.0$ & $-0.85 \pm 0.0$ & $-0.18 \pm 0.0$ \\
Maternal & Ras Elhekma & $15.98 \pm 0.0^{*}$ & $86.15 \pm 0.0^{*}$ & $131.20 \pm 0.0^{*}$ & $597.56 \pm 0.1^{*}$ & $-41.84 \pm 0.0$ \\
Genetic & Maryout & $0.01 \pm 0.0$ & $-0.15 \pm 0.0$ & $-0.22 \pm 0.0$ & $-0.12 \pm 0.0$ & $0.03 \pm 0.0$ \\
\hline
\end{tabular}

Since all values in this table were almost zeros particularly at Maryout research station, all values in this table were multiplied by $10^{-3}$ to detect any differences, if any, $(* \mathrm{P}<0.05)$. 


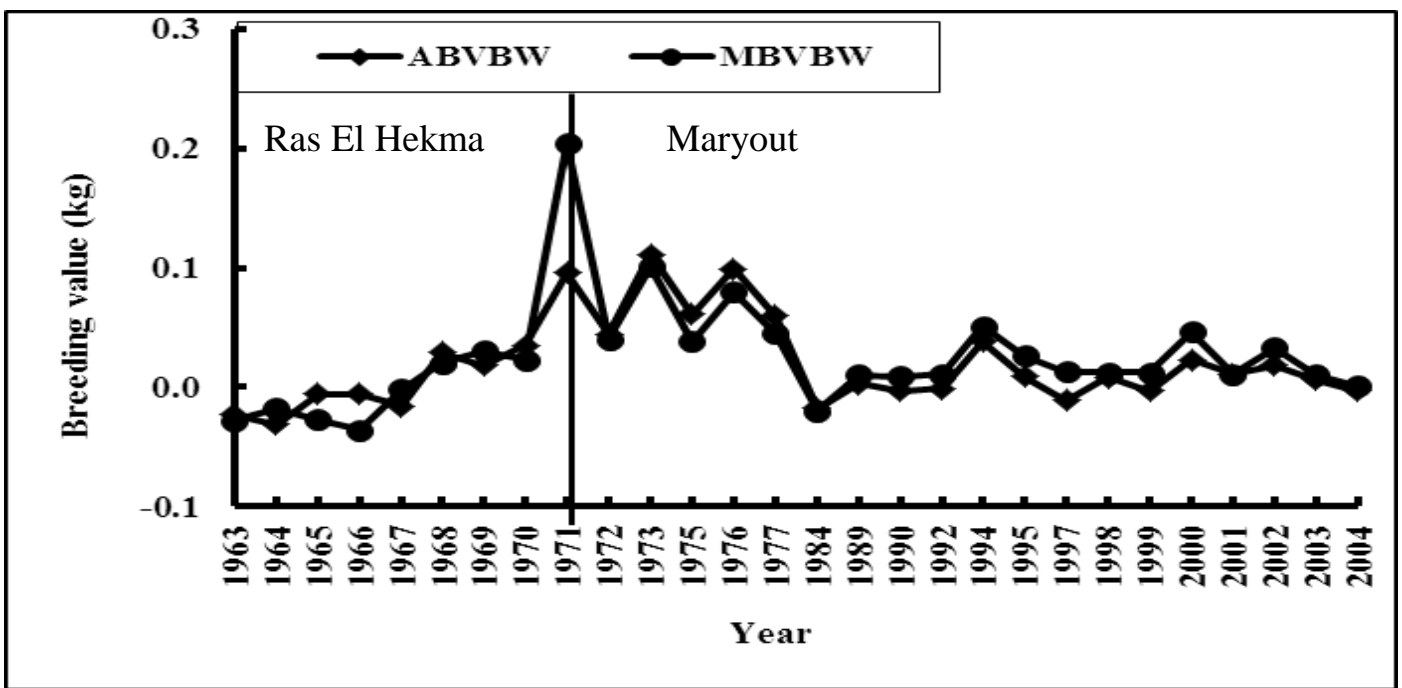

Fig. 1. Direct (additive breeding values, ABV) and maternal (maternal breeding values, MBV) genetic trends for birth weight (BW) from 1963 to 2004

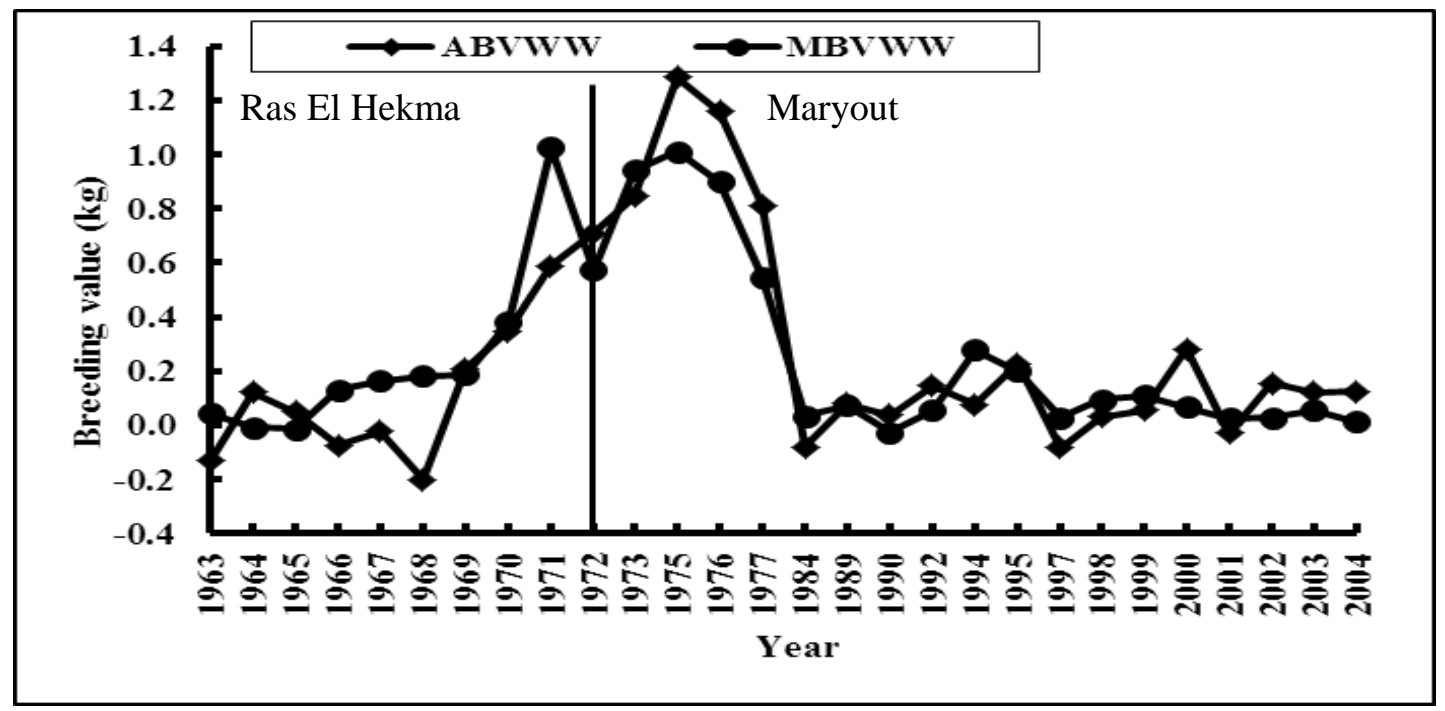

Fig. 2. Direct (additive breeding values, ABV) and maternal (maternal breeding values, MBV) genetic trends for weaning weight (WW) from 1963 to 2004

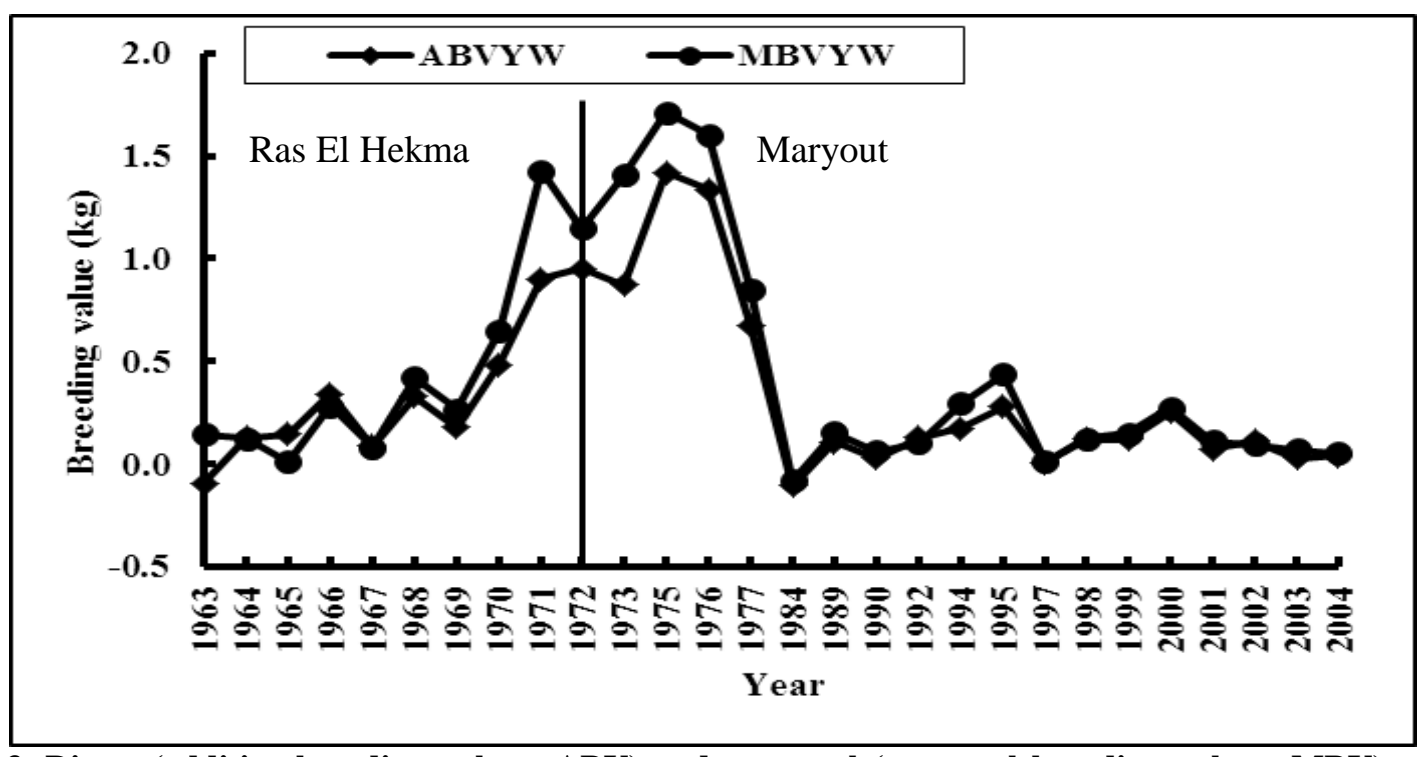

Fig. 3. Direct (additive breeding values, ABV) and maternal (maternal breeding values, MBV) genetic trends for yearling weight (YW) from 1963 to 2004 


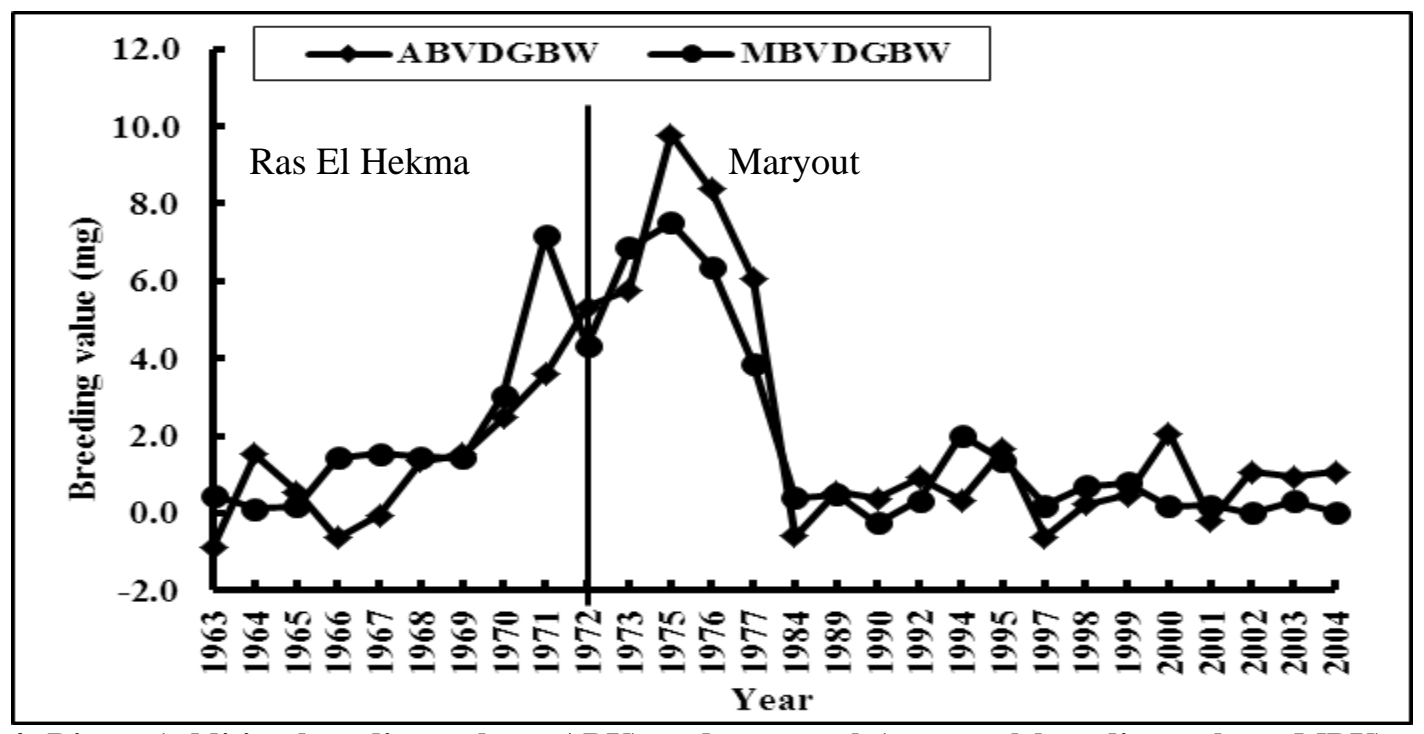

Fig. 4. Direct (additive breeding values, ABV) and maternal (maternal breeding values, MBV) genetic trends for daily gain from birth to weaning (DGBW) from 1963 to 2004

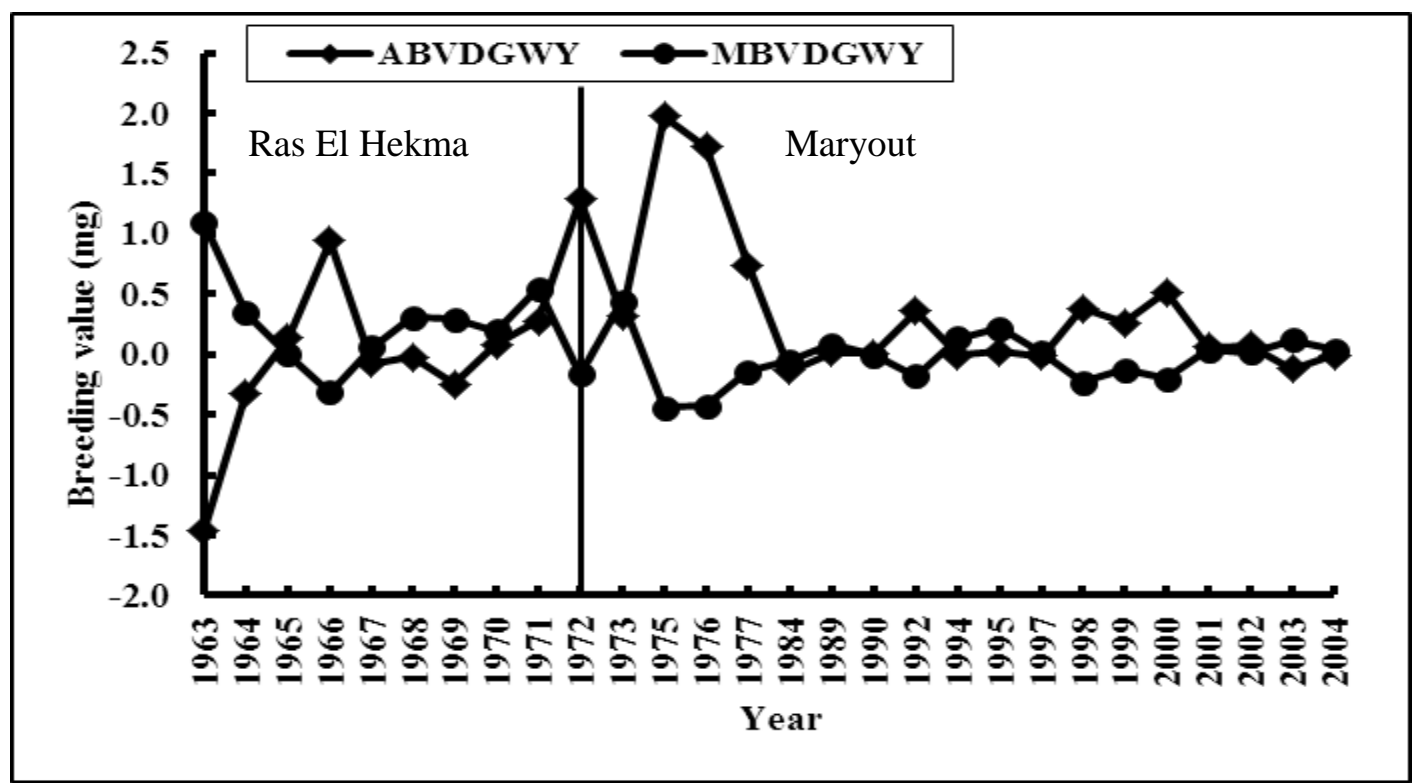

Fig. 5. Direct (additive breeding values, ABV) and maternal (maternal breeding values, MBV) genetic trends for daily gain from weaning to yearling (DGWY) from 1963 to 2004

\section{ACKNOWLEDGEMENT}

Prof. Hassanein El-Gabbas is greatly acknowledged for his valuable comments and reading the manuscript. We are grateful to the fruitful comments on the manuscript received from Dr. M. A. Snyman of Grootfontein Agricultural Development Institute, South Africa.

\section{REFERENCES}

Ahmad M., 2007. Estimated breeding values and genetic trend for milk yield in Nili Ravi buffaloes. Italy J. Anim. Sci., 6: 393-396.

Boldman K. G., L. A. Kriese, L. D. Van Vleck and C. P. Van Tassell, 1995. A manual for use of MTDFREML. A set of programs to obtain estimates of variances and covariances. US Department of Agriculture, Agriculture Research Service, Washington DC.

Burfening P. J. and D. D. Kress, 1993. Early growth traits in sheep related to their subsequent most probable producing ability. Small Ruminant Research, 7: 67-74.

El-Wakil Salwa I. and Manal Elsayed, 2013. Genetic, phenotypic and environmental trends towards improving body weight in Barki sheep. Egyptian Journal of Sheep and Goat Sciences, 8 (2): 11- 20.

El-Wakil Salwa I. and S. M. A. Gad, 2014. Evaluation of direct and maternal (co) variance components and heritabilities for some body weights and growth traits in Barki sheep. Egyptian Journal of Sheep and Goat Sciences, 9 (1): 21- 30 . 
El-Wakil Salwa I., Manal Elsayed, A. M. Ahmed, R. R. Sadek and A. A. Nigm, 2009. Genetic and phenotypic parameters of birth, weaning and yearling body weights of Barki sheep raised in the north western coast of Egypt. Egyptian J. Anim. Prod., 46 (1): 43-52.

Ghafouri-Kesbi F. and H. Baneh, 2012. Genetic parameters for direct and maternal effects on growth traits of sheep. Archiv Tierzucht, 55 (6): 603-611.

Ghafouri-Kesbi F. and M. P. Eskandarinasab, 2008. An evaluation of maternal influences, on growth traits: the Zandi sheep breed of Iran as an example. Journal of Animal and Feed Sciences, 17: 519-529.

Gowane G. R., A. Chopra, V. Prakash and A. L. Arora, 2010. Estimates of (co) variance components and genetic parameters for body weights and first greasy fleece weight in Malpura sheep. Livestock Science, 131: 94-101.

Maria G. A., K. G. Boldman and L. D. Van Vleck, 1993. Estimates of variances due to direct and maternal effects for growth traits of Romanov sheep. Journal Animal Science, 71:845-849.

Miraei-Ashtiani S. R., S. A. R. Seyedalian and M. Moradi Shahrbabak, 2007. Variance components and heritabilities for body weight traits in Sangsari sheep, using univariate and multivariate animal models. Small Ruminant Research, 73: 109-114.

Mousa E., L. D. Van Vleck and K. A. Leymaster, 1999. Genetic parameters for growth traits for a composite terminal sire breed of sheep. Journal of Animal Science, 77: 1659-1665.

Rashidi A., 2012. Genetic parameter estimates of body weight traits in Iran-Black sheep. Journal of Livestock Science and Technologies, 1 (1): 5460.

SAS, 2004. Statistical Analysis System. SAS Users Guide: Statistics. SAS Institute Inc. Editors, Cary, NC.
Senemari Mahdieh, Majid Kalantar, Saeed Khalajzadeh and Mohsen Gholizadeh, 2011. Genetic and phenotypic parameters of body weight in Zandi sheep. African Journal of Biotechnology, 10 (68): 15444-15449.

Shokrollahi B. and H. Baneh, 2012. (Co) variance components and genetic parameters for growth traits in Arabi sheep using different animal models. Genetics and Molecular Research, 11(1): 305-314.

Snyman M. A., G. J. Erasmus, J. B. Van Wyk and J. J. Olivier, 1995. Direct and maternal (co) variance components and heritability estimates for body weight at different ages and fleece traits in Afrino sheep. Livestock Production Science, 44: 229-235.

Supakorn C., Winai Pralomkarn and Suwit Anothaisinthawee, 2013. Estimation of genetic parameters and genetic trends for weight and body measurements at birth in sheep populations in Thailand. Songklanakarin J. Sci. Technol., 35 (1): 1-10.

Szwaczkowski T., J. Wójtowski, E. Stanisławska and A. Gut, 2006. Estimates of maternal genetic and permanent environmental effects in sheep. Arch Tirezucht, 49: 186-192.

Thiruvenkadan A. K., K. Karunanithi, J. Muralidharan and R. Narendra Babu, 2011. Genetic analysis of pre-weaning and postweaning growth traits of Mecheri sheep under dry land farming conditions. Asian-Aust. J. Anim. Sci., 24(8):1041-1047.

Tosh J. J. and R. A. Kemp, 1994. Estimation of variance components for lamb weights in three sheep populations. Journal of Animal Science, 72: 1184-1190.

Ulutas Z., M. Sezer, M. Saatci and A. Sahin, 2010. Estimation of genetic and phenotypic trends of 305-day milk yield for Simmentals reared in Kazova state farm in Turkey. Kafkas Univ. Vet. Fak. Derg., 16 (4): 533- 536. 


\section{المعالم الوراثية المباشرة والأمية والاتجاهات الوراثية لبعض أوزان الجسم وصفات النمو في الأغنام البرقي}

سلوى إبراهيم الوكيل ، سليمان محمد على جاد

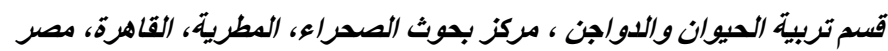

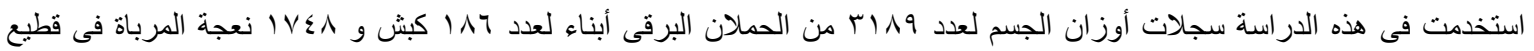

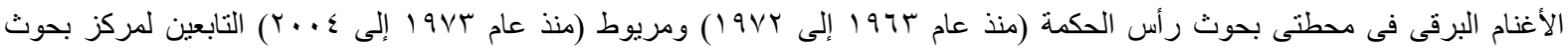

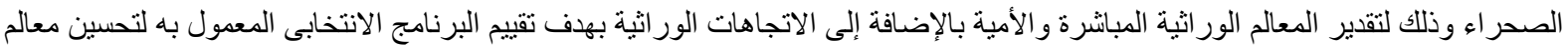

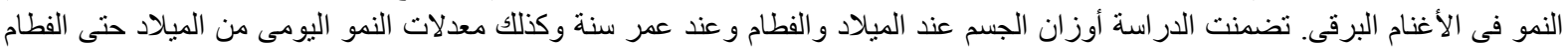

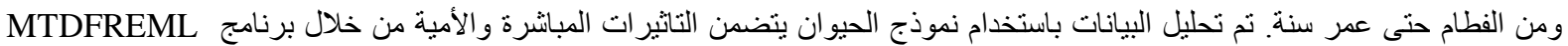

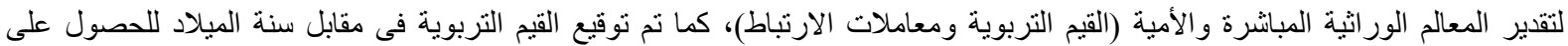
الاتجاهات الور اثية للصفات المدروسة.

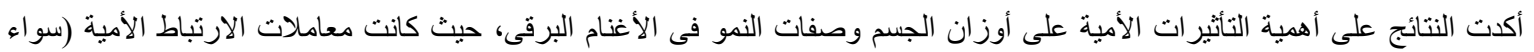

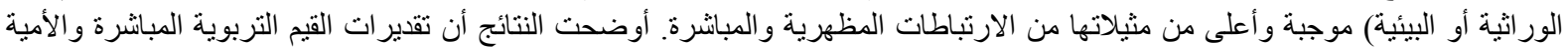

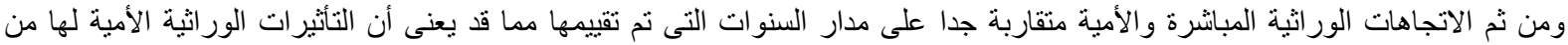

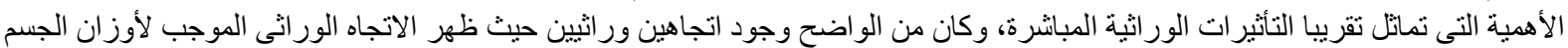

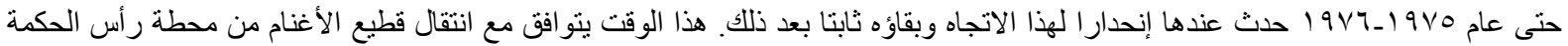

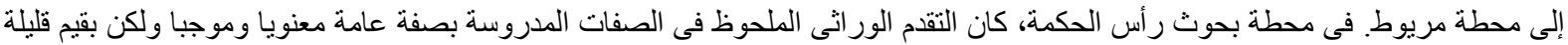

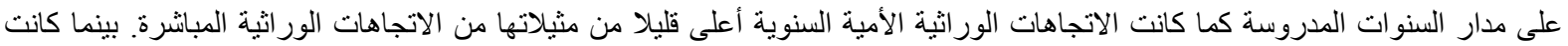

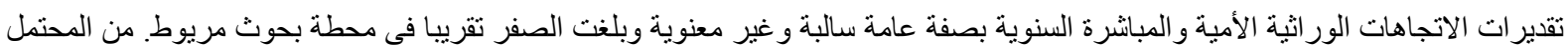

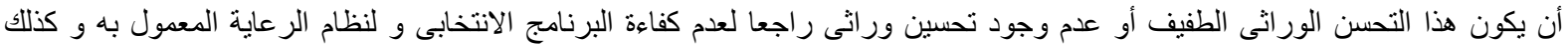

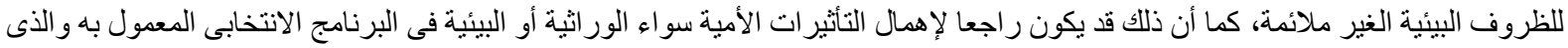

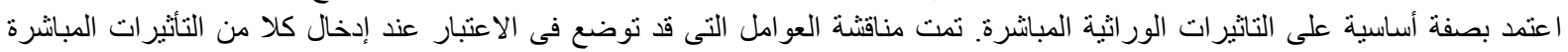
و الأمية فى البرنامج الانتخابى لتحسين أوزان الجسم و صفات النئ النمو فى الأغنام البرقى. 